REVISTA ANDALUZA DE ANTROPOLOGÍA

NÚMERO 14: IRRUPCIONES FEMINISTAS. PROBLEMÁTICAS EPISTEMOLÓGICAS Y POLÍTICAS. FEMINIST EMERGENCES. EPISTEMOLOGICAL AND POLITICAL ISSUES

MARZO DE 2018

ISSN 2174-6796

[pp. 200-202]

http://dx.doi.org/10.12795/RAA.2018.14.12

\title{
FALQUET, JULES (2016). PaxNeoliberalia, perspectives feministes sur (la réorganisation de) la violence. Paris: ÉditionsiXe, 192 pp.
}

\section{Lourdes Méndez}

Universidad del País Vasco/Euskal Herriko Unibertsitatea

Voy a iniciar esta breve reseña haciendo referencia a cómo, tras cuatro ensayos escritos en diferentes fechas yen los que analiza -en El Salvador, Turquía, México y Guatemala- el continuum de la violencia contra las mujeres desde el feminismo materialista francés, finaliza su libro Jules Falquet. La socióloga pone el punto final a sulibro no con su escritura, no con sus análisis, sino con un poema de Melissa Cardoza dedicado a la memoria de Berta Cáceres, la líder indígena lenca, feminista, activista en defensa del medio ambiente, asesinada el 3 de marzo de 2016 en Honduras. Y ese punto final, opción de serio calado político, hace emerger en el libro un país, Honduras, que se añade así, en filigrana, a los otros cuatro en los que Falquet centra su análisis sobre el carácter estructural de la violencia ejercida contra las mujeres tanto en espacios públicos como privados.Un análisis llevado a cabo desde una perspectiva materialista de des-naturalización y despsicologización de la violencia,que concierne a objetos de estudio diversos, y que está basadoen materiales heterogéneos. A pesar de esa heterogeneidad, los cuatro ensayos dan cuenta del avance de la mundialización neoliberal, del ensamblaje de sus lógicas destructivas, y del incremento e interpenetración "de diferentes dinámicas de violencia y de guerra. La reorganización de la coerción que se desarrolla bajo nuestra mirada nos habla de un inquietante futuro que asoma bajo el barniz de lo que propongo llamar 
Paxneoliberalia -ese estado paradójico e inestable en el que hoy en día nos encontramos. Veremos que en él es central la violencia contra las mujeres"(Falquet, 2016: 24). El tono del libro está dado.

En el primer ensayo, escrito hace veinte años como parte de su futura Tesis, la socióloga analiza la violencia doméstica en El Salvador y nos propone entenderlaen términos de tortura, como elemento clave de una guerra de baja intensidad, y planteándola como una práctica estructural. Una forma de entenderlaque, explicaFalquet en la introducción de su libro, impulsó a su director a sugerirle que eliminara esa parte de su Tesis. Los otros tres ensayos son recientes. En el segundo el interés de su autora lo despierta la investigación de una socióloga turca, Pinar Selek, sobre el servicio militar en Turquía. El análisis de Falquet, basado en los datos de Selek, se centra en la institución del servicio militar, en su obligatoriedad para los hombres, y en el hecho de que durante el periodo de tiempo que dura,el Estado, además de organizar la enseñanza de la violencia, asegura que sea un grupo social en especial - en este caso los hombres-el que ostente su monopolio. En el tercero, son los feminicidios de Ciudad Juarez los que atraen su atención, esos asesinatos, violaciones y torturas de diversos tipos que desde principios de los noventa del pasado siglo se producen en la frontera norte de México, espacio geopolítico y económico que Falquet califica como "verdadero laboratorio de la mundialización" (id: 18). Por último, en su cuarto ensayocentra su atención sobre las luchas (de) coloniales en torno al Territorio y propone un complejo recorrido que lleva de las violencias sexuales durante la guerra de principios de los ochenta en Guatemala,hasta la actualidad en la que impera un extractivismo minero transnacional neoliberal. Movilizándose contra el extractivismo, señala Falquet, "Algunas mujeres Indígenas han desarrollado una nueva corriente de análisis y acción, el 'feminismo comunitario', que afirma alto y fuerte la imperiosa necesidad de ligar la defensa del Territorio-Tierra a la del Territorio-Cuerpo, y en particular del cuerpo de las Indígenas, objeto de todas las violencias desde hace más de cinco siglos"(id: 22). Es en este último ensayo en el que Falquet, ahonda en las posibles potencialidades de las epistemologías del sur desarrolladas por y desde diversos colectivos en lucha que se organizan más allá de las estructuras políticas tradicionales. Como ya he señalado, nos encontramos ante ensayos basados en materiales heterogéneos y a prácticas de violencia contra las mujeres que tienen lugar en diferentes países. Lo que une entre sí estos ensayos es la propuesta teórica de Falquet de analizar sus diferentes objetos de estudio, insertados en el contexto de la mundialización neoliberal, desde la perspectiva del feminismo materialista sin cejar en el empeño de mostrar el carácter sistémico y estructural del continuum de la violencia ejercida contra las mujeres. La socióloga recurriráen los análisis que nos propone a algunas de sus autoras de referencia, artífices del feminismo materialista francófono -Guillaumin,Tabet- haciendo uso de nociones por ellas acuñadas como la de 'clase sexo' (Guillaumin). Esa opciónle permite desnaturalizar radicalmente las violencias contra las mujeres y alejarse de los 
análisis de corte simbólico y psicologizante sobre la misma para aprehenderla como un conjunto de prácticas específicas y organizadas, en los diferentes países, por diversos grupos (financieros, militares, paramilitares), o por el propio Estado, con el objetivo de mantener a la 'clase mujeres' en una posición estructural de dominadas, y de impedir todo intento de organización y rebelión generando un sutil régimen de terror sexuado que penetra en todos los espacios donde la 'clase hombres' ejerce su opresión y participa en lo que la socióloga denomina una 'guerra de baja intensidad' contra la 'clase mujeres'. La riqueza del libro de Jules Falquet, la sutileza de su análisis hacen de Paxneoliberalia un texto de lectura más que recomendable para todas aquellas personas deseosas de seguir elaborando análisis críticos feministas sobre las complejas realidades del mundo en el que vivimos. 